ACKNOWLEDGEMENT

We wish to thank all staff at Charlotte Keel Health Centre for their help.

\section{REFERENCES}

${ }^{1}$ Gibson, R., Forbes, J. M., Stoddart, I. W., COOKE, J. T., Jenkins, C. W., MACKetth, S. A., Rosenberg, L., AllChn, W. H. \& SHIEPHERD, D. (1966) Psychiatric care in general practice: an experiment in collaboration. British Medical Journal, 1, 1287-1289.
${ }^{2}$ MitchelL, A. R. K. (1985) Psychiatrists in primary health care settings. British Journal of Psychiatry, 147, 371-379.

${ }^{3}$ Tyrer, P., Seivewright, N. \& Wollerton, S. (1984) General practice psychiatric clinics: impact on psychiatric services. British Journal of Psychiatry, 145, 15-19.

4World Health Organization (1973) Psychiatry and Primary Medical Care. WHO Regional Office for Europe, Copenhagen.

${ }^{5}$ TYRER, P. (1984) Psychiatric clinics in general practice, an extension of community care. British Journal of Psychiatry, 145, 9-14.

${ }^{6} \mathrm{JONES}, \mathrm{K}$. (1979) Integration or disintegration in the mental health service. Journal of the Royal Society of Medicine, 72, 640-648.

A full list of references is available from $\mathrm{Dr}$ Browning on request.

\title{
Assessing Patients in their Homes
}

S. J. JonEs, Research Associate, Nottingham Psychiatric Case Register, University Department of Psychiatry, Queen's Medical Centre, Nottingham; R. J. TURNER, Consultant Psychiatrist, South and West Nottingham Mental Health Team and J. E. GraNT, Senior Social Worker, South and West Nottingham Mental Health Team, 19 Regent Street, Nottingham

General adult psychiatric services in Nottingham operate on a sector basis, with clinical teams having responsibility for the psychiatric care of all patients resident in a defined area. Sectors, which are conterminous with two or more social service areas, are not of equal population size, but comprise populations likely to give rise to similar demands for psychiatric services. The Social Services Department responded to the introduction of full sectorisation of hospital services in 1982 by allocating social workers to sector teams where possible, aiding the development of multidisciplinary teams.

The first major development was the establishment of the South and West Nottingham Mental Health Team. In October 1982 a community base was acquired in the city centre, which is also central to the area served by the team. A multidisciplinary team was set up, consisting of two consultant psychiatrists, a senior registrar, two senior house officers, a senior and three social workers, an occupational therapist, two community nurses and a psychologist. In-patient ( 28 beds) and day care facilities are based in the psychiatric unit of a district general hospital. The team provides a comprehensive general adult psychiatric service to people aged between 16 and 64 who are assessed by other agencies (GPs, probation and social services) as being in need of psychiatric help. There is continued access to specialist services such as alcohol and addiction, forensic and rehabilitation facilities. The team has responsibility for a catchment area population of 94,000 .

The organisation of the provision of psychiatric care has markedly changed since the inception of the team. In contrast to conventional practice it was decided that initial assessment of patients should be undertaken in patients' homes, unless there were good reasons not to do so. Unlike first contacts which are made in out-patient clinics, where assessment is carried out solely by medical staff, the team has adopted joint assessment by the two members con- sidered most appropriate based on the referral information. A weekly out-patient review meeting has been instituted in order that all referrals can be discussed by the team as a whole and selection made of team members to undertake specific assessments. Since these first assessments are arranged at times mutually convenient to team members and patients, there is greater flexibility than if they had to take place at regular scheduled out-patient clinics. Urgent referrals are still normally seen on the day of referral.

Following the initial assessment visit, a report is made to the next team meeting and one, or sometimes two, key workers are identified to take responsibility for the agreed programme of care. They are responsible for any follow-up that is considered necessary and will involve other members of the team as appropriate. It is understood that any change of direction in the person's care will be discussed wherever possible with the key worker, in an attempt to provide continuity and consistency. If necessary, follow-up may be continued at home.

The style of working adopted by the team is generally preferred by team members. A survey of both patients referred and their general practitioners was undertaken to ascertain their preferences, particularly concerning the introduction of home visits for initial assessment. Additionally an examination was made of the speed of response to referrals and the extent to which different disciplines undertook both initial assessment and subsequent key worker roles.

\section{Methods}

Basic details of all patients referred have been recorded since the inception of the team. These include age, sex, source of referral and the time interval between receipt of referral and assessment. Information about the assessors and place of contact of the initial assessment, together with subsequent key worker, were also available. The figures for 
1983 and 1984 were examined separately to determine whether there were any noticeable trends.

A questionnaire was sent to patients who were seen at home by the team following a non-urgent referral between September 1984 and May 1985. Reminder letters were not sent out, to avoid any problems which might have arisen with patients who were in continuing care. Questions included preference for place of first contact and the number and sex of assessors. Patients were asked whether they thought that the assessors had understood more by seeing them at home, and whether they agreed with five statements about aspects of where they might be seen (waiting time, convenience, relaxed atmosphere, ease of talking and other people knowing about their problems). The option of 'don't know' was given if people were unable to decide or had no experience of hospital clinics.

A questionnaire was sent to all general practitioners with surgeries in the area served by the team. They were asked to state their preferred place for initial assessment and whether they were generally happy with the speed of response to referrals. Further questions related to the general impression of the team, whether in fact they had noticed any difference in the service provided, or had any response from patients. Details of the number of doctors in each practice, and whether they had a particular interest in any medical speciality were also obtained. Year of registration for each doctor was recorded.

\section{Results}

There were 339 referrals to the team in 1983 and 337 in 1984. In each year $42 \%$ of patients referred were male. The age distribution of patients referred was similar in both years, with $40 \%$ aged between 15 and 34 and $36 \%$ between 35 and 54 . In $1983,93 \%$ of patients were referred by general practitioners but in 1984 the proportion had dropped to $85 \%$. In both years $65 \%$ of patients were seen within one week; however, the proportion seen within the following week rose from $16 \%$ in 1983 to $24 \%$ in 1984 . The involvement of different categories of staff in the assessment of patients remained largely unchanged between 1983 and 1984, except for the increased contribution of the psychologists as a result of changes in personnel. The percentages of patients seen per staff member add up to less than 200 , since some patients were seen by a single team member either because it proved impossible to arrange joint assessment or patients were seen in conjunction with another worker, such as a probation officer or a social worker from an area office. The proportion of people referred who were offered follow-up was $63 \%$ in 1983 and $75 \%$ in 1984.

In both years, a majority of patients $(60 \%)$ were assigned a member of the medical staff as key worker. In 1983 social workers became key workers for almost a third of patients but this proportion fell to less than $20 \%$ in 1984 , largely because one of the social workers took over responsibility for development work. The pychologist involvement as key worker rose from $2 \%$ in 1983 to $18 \%$ in 1984 , whilst community nurses became the key worker for an eighth of patients in both years.

\section{Patients' attitudes to firs! assessment at home}

Questionnaires were sent to 200 patients and 123 (62\%) were returned from 61 males and 62 females. The majority $(72 \%)$ stated a preference for being seen at home $(61 \%$ of men and $82 \%$ of women). Out-patient clinics or general practitioner surgeries were preferred by $12 \%$ of people. Of the $17(14 \%)$ who did not mind where they were seen, 15 were men. The majority ( $80 \%$ ) felt that the assessors had gained a better idea of their difficulties because they were seen at home. The proportion was the same for both men and women.

Almost half $(42 \%)$ of people stated that they did not mind whether they were seen by one or two people or what sex they were. Over a third (36\%) preferred to be seen by one person, with women tending to prefer one woman and men one man.

Most people (66\%) agreed with the statement that it is easier to talk at home and disagreed $(61 \%)$ that there is a more relaxed atmosphere at the clinic. The clinic was considered neither more convenient nor associated with less waiting time. Although not statistically significant, there was a tendency for women to favour home visits more than men, particularly for convenience. A third (29\%) thought that more people got to know about problems if seen at the clinic, a third (33\%) disagreed and the rest did not know.

\section{General practitioner attitudes to the team}

Questionnaires were sent to 66 general practitioners and $54(82 \%)$ were returned, of which 42 were male. Over half $(54 \%)$ had qualified prior to 1970 . The majority (69\%) felt that patients were seen quickly enough but $12(22 \%)$ did not.

Over half gave home as the preferred place for assessment although many gave it as an option with either out-patient clinics or general practitioner surgeries. Very few chose the out-patient clinic as the preferred place of assessment and almost a quarter stated no preference. Over half $(52 \%)$ had noticed no difference since the team was set up; however $85 \%$ of those who had noticed a difference stated that there was an improvement, generally that the service was quicker and more comprehensive, with easier access to non medical disciplines. No general practitioner stated dissatisfaction with the service, although $28 \%$ did not answer and $19 \%$ felt that they did not know because they had referred none or very few patients. The numbers were small but those most recently qualified were more likely to state that they were satisfied with the team. The majority $(72 \%)$ stated that they had had no response from patients to the team. Several very positive comments from patients were reported, but no adverse ones.

\section{Discusion}

Clearly the flexible arrangements for initial assessments which have been adopted by the team have proved successful in achieving a prompt response, with the majority of 
patients being seen within a week of referral. This contrasts with the situation in the two years immediately prior to the introduction of home assessments, when the rigidity inherent in conventional scheduled out-patient clinics often resulted in patients having to wait up to six weeks for an appointment. Several general practitioners were favourably impressed by the speed of response, and it may have contributed to the favourable opinion of home assessment expressed by patients.

Although home visits were introduced to improve the assessment of social circumstances and family relationships, they have been appreciated by the patients themselves. Most people positively preferred to be seen at home, indicating that it was the more relaxed atmosphere with the greater ease in talking that made being seen at home preferable. This perhaps explains why a majority felt that the assessors got a better understanding of their difficulties. Although it was hoped that home visits would lead to a greater involvement of other family members, it was recognised that there could be a loss of privacy for patients. The team has tried to be sensitive to this and to ensure that the right to privacy is respected, for example by offering assessment at the team's offices rather than at home. This appears to have been successful, with no patients making adverse comments about a lack of privacy.

Joint assessment by pairs of team members from different disciplines was intended to maximise the range of perspectives, knowledge and skills brought to each interview and to lessen the chances of overlooking important aspects of the problem. The opportunity is created to understand and to value the contribution of other disciplines and to provide valuable learning opportunities for less experienced workers. General practitioners stated that they preferred the availability of the range of skills offered and that patients had also commented favourably, particularly about social work involvement. A significant number of people stated that they would prefer to be seen by one person, usually of the same sex as themselves. Single assessment may present difficulties of clinical responsibility, but if blurring of roles within the team is occurring to any great extent then this might be feasible when referrals are comprehensive and clear enough to indicate the predominant skills which might be appropriate to the person referred.

The operation of the South and West Nottingham Mental Health Team is obviously different to more conventional methods and to many of the community mental health teams which have been set up in recent years. ${ }^{1,2.3 .4}$ It offers a comprehensive general adult psychiatric service to all patients conventionally referred rather than concentrating on crisis intervention or a walk-in service. The experience of the team may have general applicability since it has operated in an area representative of most of England and Wales. Nottingham is a typical moderate-sized industrial town, neither particularly affluent nor deprived, ${ }^{5}$ and overall the pattern of use of psychiatric services reflects the national average. ${ }^{6}$ However the team has responsibility for two social service areas which have populations making varying demands on services. The rate of total new outpatient episodes in 1982 for all of Nottingham was 100.9 per 10,000 population, whilst that for the south area was 85.7 and for the west area 140.9. The team's area includes part of the inner city area of Nottingham as well as a large housing estate, a recently redeveloped slum area and some suburban community areas.

The team which has been developed does not represent a 'special' service and since Nottingham itself represents an average area, such facilities could be implemented in most areas. On the basis of present information, it seems fairly clear that team members, patients, and referring agencies, such as general practitioners, are happy with the style and organisation of working that has been developed, but further evaluative work is being undertaken, in particular comparing subsequent patterns of care, and their costs, with traditional working practices.

\section{REFERENCES}

'Bouras, N., Tufnell, G., Brough, D. I. \& Watson, J. P. (1986) Model for the integration of community psychiatric and primary care. Journal of the Royal College of General Practitioners, 36, 62-66.

${ }^{2}$ Hutron, F. (1985) Self-referrals to a community mental health centre: a three year study. British Journal of Psychiatry, 147, 540-544.

${ }^{3}$ JoNES, D. (1982) The borders mental health service. British Journal of Clinical and Social Psychiatry, 2, 8-12.

${ }^{4}$ Scort, R. D. (1980) A family orientated psychiatric service to the London Borough of Barnet. Health Trends, 12, 65-68.

${ }^{5}$ WebBer, R. J. \& Cralg, J. (1978) Socio-economic Classification of Local Authority Areas. Studies in Medical and Population Subjects No. 35. London: HMSO.

${ }^{6}$ UK Registers Group (1984) Psychiatric Care in Eight Register Areas.

\section{Lithium Congress}

The 2nd British Lithium Congress will be held at Compton Park Centre, Wolverhampton Polytechnic, from 6-9 September 1987. Recent developments in lithium usage and new pharmacological and biochemical knowledge will be discussed. Further information can be obtained from Dr N. J. Birch, Biomedical Research Laboratory, Centre for Health Sciences, The Polytechnic, Wolverhampton WV1 1LY. 